RESENHA / REVIEW 
SCHARAGRODSKY, Pablo. (Comp.) Miradas médicas sobre la cultura física en Argentina (1880-1970). Coleção: sujetos, políticas, educación.

Buenos Aires: Prometeo Libros, 2014.

Carmen Lúcia Soares*

Universidade Estadual de Campinas (UNICAMP)

André Dalben**

Pontifícia Universidade Católica de São Paulo (PUC-SP)

\section{PODERES E PROPOSTAS NA CONFORMAC̣̃̃O DE UMA CULTURA FÍSICA NA ARGENTINA (1880-1970)}

\section{POWERS AND PROPOSALS IN THE CONFIGURATION OF A PHYSICAL CULTURE IN ARGENTINA (1880-1970)}

O livro em questão, organizado por Pablo Scharagrodsky, um dos pesquisadores mais conceituados no campo da história da Educação Física e inspirado pelas teorias foucaultianas, reúne conjunto significativo de trabalhos de pesquisa que tratam da história da cultura física na Argentina, no período que compreende os anos de 1880 a 1970. Partindo de enfoques metodológicos e de perspectivas teóricas distintas, os trabalhos que compõem a obra tomam a cultura física como objeto de estudo compreendendo-a como terreno de conflitos no qual distintos atores, instituições e grupos sociais produziram e fizeram circular uma complexa rede de significados e de conceitos marcadamente heterogêneos. Não se trata de pensar apenas em um corpo orgânico e em seu funcionamento "normal", tampouco em suas performances verificáveis em inúmeras esferas da vida, mas, sim, e de modo muito especial, temas e problemas que excedem o universo biológico e que agregam múltiplos sentidos, por vezes

\footnotetext{
http://dx.doi.org/10.1590/0102-4698143185

* Doutora em Educação pela Universidade Estadual de Campinas (UNICAMP). Professora Livre-docente do Programa de Pós-Graduação em Educação da Universidade Estadual de Campinas (UNICAMP). Bolsista de Produtividade em Pesquisa CNPq-2. E-mail: carmenls@unicamp.br

* Doutor em Educação pela Universidade Estadual de Campinas (UNICAMP). Pós-doutorando em História pela Pontifícia Universidade Católica de São Paulo (PUC-SP) e bolsista da Fundação de Amparo à Pesquisa de São Paulo (FAPESP - Processo no. 14/111535). E-mail: andredalben@yahoo.com.br
} 
ambíguos, contraditórios, polissêmicos acerca da degenerescência física, da deterioração biológica, da degeneração racial, assuntos caros ao recorte temporal inicial da obra. A nacionalidade ligada ao progresso somático e à pátria, tema que leva ao debate da argentinidade agregado às discussões acerca da sexualidade e das emoções, do desejo e de certo tipo de feminilidade e masculinidade associadas a determinada moral, percorre os textos e é aqui problematizada. Saúde, higiene e doença associam-se aos conceitos de "normalidade" e "anormalidade", desenhando quais seriam os desvios, o que seriam a beleza e a feiura físicas e sua relação com a maldade e a bondade, relação esta, sem dúvida, arbitrária; são esses alguns dos muitos temas que percorrem a obra. É desse universo conceitual e teórico que surge o debate em torno da Educação Física na Argentina, expressão significativa do que se considerou, naquele país, uma cultura física e que é detalhada pelos autores reunidos na obra.

Ao empregarem distintas perspectivas teóricas e metodológicas, os autores apresentam ao público leitor sofisticadas e instigantes análises sobre a história da Educação Física, não se restringindo unicamente ao ambiente escolar, mas abordando diversos outros cenários, como os de clubes, ginásios, praças de esportes, colônias de férias, acampamentos, entre tantas outras instituições extraescolares. A obra parte da premissa de que, ao mesmo tempo que o saber médico conferiu as principais bases para a legitimação da Educação Física em diferentes contextos políticos, econômicos e culturais argentinos, a manteve em situação de dependência, excluindo, omitindo ou silenciando outras possíveis alternativas de se vivenciar a experiência corporal que não estivessem atreladas e dependentes da ordem médica.

O capítulo escrito por Scharagrodsky analisa a formação do currículo do Instituto Nacional de Educación Física ${ }^{1}$ como um campo de batalha onde se criara um processo de seleção de conteúdos, práticas e saberes médicos considerados legítimos, adequados e corretos para o ofício do profissional da Educação Física na Argentina das primeiras décadas do século XX. Atravessada por esse discurso, a matriz educativa do instituto foi construída sob a égide da anatomia e da fisiologia, disciplinas científicas que silenciaram e sujeitaram as matérias práticas e didáticas, desejando afirmar seu capital simbólico e destino político. A formação oferecida ao professor de Educação Física se manteria não apenas sob tutela médica, mas também sob sua vigilância, transformando, assim, o profissional da Educação Física ali formado em um mero aplicador de práticas e princípios da medicina, ou, nas palavras do próprio autor, em um "médico de menor ordem". 
Analisando as funções centrais do sistema de ensino argentino, Angela Ainsenstein se dedicou ao currículo da educação primária, investigando a inserção de componentes da Educação Física e da educação alimentar entre os saberes escolares do período. Tomando como marco conceitual os processos de medicalização da sociedade, a autora analisou o modo como temas que antes não eram considerados ou problematizados como pertinentes ao campo da medicina começaram a ser por esta definidos e penetraram no discurso pedagógico escolar. São exemplos os divertimentos e as preferências alimentares, pois passaram a ser tratados a partir de uma seleção específica e de adaptação aos cânones científicos da fisiologia, no caso da Educação Física, e da bioquímica, no que se refere à educação alimentar. Postos a serviço da saúde infantil, determinados exercícios físicos e certos alimentos seriam valorizados por teses médicas em detrimento de outros considerados prejudiciais ou pouco proveitosos. Assim, segundo a autora, o país estaria diante de um desejo de homogeneização científica que escamotearia particularidades sociais e culturais, de modo a conformar uma biopolítica curricular específica para escolas do ensino primário argentino.

No que diz respeito à homogeneização científica posta em prática pela vinculação da Educação Física aos saberes médicos do período, Andrea Torricella analisa a materialidade das fotografias tiradas pelo laboratório fisiológico do Instituto Nacional de Educación Física como suporte favorável para a construção de uma racionalidade médico-científica sobre o corpo, a qual procurava se afirmar como hipoteticamente isenta de mediação. Enquanto uma tecnologia que se pretendia objetiva, a fotografia corroborou não apenas modos específicos de representar o corpo humano e suas patologias, mas se estabeleceu também como uma forma de registrar comportamentos e gestos moralmente aceitos pela sociedade argentina da primeira metade do século XX. A pesquisa revela que as fotografias compuseram parte dos esforços médicos de controlar e normalizar os corpos dos indivíduos a partir de uma racionalidade científica conferida para a Educação Física.

Entre os saberes médicos do período, a eugenia foi certamente a expressão mais austera e restritiva para a Educação Física argentina. $\mathrm{Na}$ obra, aparece tanto como eixo central quanto como componente de estudos em diferentes capítulos. É nesse sentido que Andrés Reggiani abordou a "nova religião científica" do fim do século XIX. Mais do que diferenciá-la de medidas higiênicas e de saúde pública, a pesquisa analisou as especificidades do pensamento eugênico na 
Grã-Bretanha, na França e na Argentina, de modo a traçar suas influências nos campos da Educação Física desses países. Apoiada geralmente em diagnósticos pessimistas sobre as condições de vida das populações, em estatísticas nem sempre fidedignas, a eugenia estabelecia a convicção de que todos os problemas poderiam ser solucionados a partir da racionalidade científica, sobretudo biológica. O pensamento eugênico alcançaria, em muitos casos, a supremacia nos discursos que respaldavam a intervenção estatal por meio de ações que priorizavam a Educação Física.

Os discursos médicos de influência eugênica também constituíram o eixo de investigação de Lucía Lionetti ao problematizar o paradigma da normalização dos corpos infantis desviantes da média antropométrica, instituída pelo saber biomédico do período. Este saber foi responsável pela formulação de uma série de estigmas sociais sobre as crianças desvalidas oriundas de famílias pobres, atendidas pelas colônias de férias, por escolas ao ar livre e cantinas escolares portenhas. Embasada em tradicionais análises historiográficas que tomavam como referência principal os estudos foucaultianos, a autora define a ação destas instituições como uma terapêutica das anormalidades corporais, animada pelo desejo de reeducar, corrigir ou adaptar o organismo infantil qualificado como anormal aos ditames morais da eugenia argentina. Segundo suas análises, essas três instituições extraescolares conseguiram grande ascensão nos meios eugênicos devido aos desejos de homogeneizar as diferenças, de vigiar e controlar o corpo infantil, excluindo-o ou tornando-o útil aos projetos de nação defendidos por setores conservadores da sociedade argentina. Captando o que escapa e que não é alcançado pelos controles, a autora indica em suas conclusões que, na prática cotidiana das instituições que pôde interpretar, sobretudo nas colônias de férias, as crianças atendidas desfrutaram de viagens a localidades desconhecidas, experienciando singulares rotinas, muito distantes daquelas vivenciadas no duro cotidiano urbano de suas famílias operárias.

Esta questão em específico foi também o ponto central de investigação de Diego Armus ao tomar como objeto de análise as escolas ao ar livre e as colônias de férias na Argentina. $\mathrm{O}$ autor analisou estas instituições assistenciais, ou caritativo-filantrópicas, não apenas por meio do discurso eugênico, mas considerando também a preocupação médica com a cura e a prevenção da tuberculose, doença que tanto inquietava a população e os administradores públicos na época devido às elevadas taxas de mortalidade. Pôde o autor, desse 
modo, concluir que, diferentemente das intenções reparadoras e disciplinadoras dos sanatórios e dos hospitais especializados nesta enfermidade, as colônias de férias e as escolas ao ar livre argentinas foram, antes de tudo, um recurso educativo extraescolar e um importante instrumento de reforma social. Mais do que o melhoramento físico das novas gerações e a preocupação em se forjar uma raça nacional, como corriqueiramente apresentavam os discursos eugênicos, os conteúdos postos em prática por estas instituições foram de assistência social, oferecendo alimentação farta e espaços educativos antes inexistentes para as crianças pobres. $\mathrm{O}$ autor considera exagerado analisá-las como sofisticadas estratégias de modelação dos corpos e das almas das crianças, exatamente porque essas instituições apresentavam um conjunto de valores associados à liberdade e à responsabilidade individual, à sociabilidade e à vida em comunidade. Ao estimular o exercício mais ou menos livre da imaginação na aprendizagem e o contato constante com a natureza, esse projeto educativo animaria laços fraternais e ações solidárias, distanciando-se, portanto, de um projeto refinado de disciplinamento e controle.

Postos em sequência, os dois capítulos dedicados às colônias de férias e às escolas ao ar livre portenhas apresentam ao leitor duas facetas distintas de um mesmo objeto de pesquisa, constituído por análises elucidativas e sofisticadas. Há aqui a preocupação em evidenciar as possíveis distâncias que poderiam tomar os discursos que embasavam a criação destas instituições e as suas práticas cotidianas. Isso porque os desejos eugênicos de instauração de uma forma de controle repressivo, apesar de se pretenderem uníssonos no âmbito dos discursos médicos sobre as colônias de férias e as escolas ao ar livre do período, parecem insuficientes para explicar integralmente a atuação que estes estabelecimentos extraescolares tiveram na sociedade argentina. Talvez tenha sido exatamente nesse sentido que Dora Barrancos escreveu no prefácio do livro que, para além dos desejos de controle corporal, não se pode excluir das práticas corporais a sua contribuição para a experiência prazenteira, para a ampliação das possibilidades de desfrutes vivificantes. É certo que o discurso médico se pretendeu majoritário, procurando se afirmar como único habilitado para construir e consolidar saberes sobre o corpo, a cultura física e a Educação Física. Essa história, no entanto, também foi produzida por outras instâncias, entre as quais aquela do próprio corpo que se pretende festa, que deseja se libertar das amarras do poder médico mais biologizante e estigmatizante, 
que busca superar convenções criadas por setores específicos da sociedade, ou seja, daquele corpo que desafiava o próprio poder instaurado pelo discurso médico.

Quanto aos constantes jogos de poder que procuravam enredar este corpo que impassivelmente tentava escapar da ordem médica, Patricia Anderson selecionou para seu capítulo as representações veiculadas por revistas esportivas sobre os feitos atléticos de mulheres em provas e campeonatos disputados entre 1920 e 1930. Mais do que a habilidade feminina em se destacar no mundo esportivo, em superar os desafios impostos pelas competições, as reportagens conferiam destaque, sobretudo, aos imperativos da maternidade e de um ideal de feminilidade. Tratavase, novamente, do discurso médico operando de modo a distanciar os sujeitos de sua prática cotidiana, apresentando formulações teóricas que circunscreviam o corpo feminino à sua esfera estritamente biológica e reprodutiva. Os exercícios físicos, quando realizados por mulheres, eram reverenciados como uma forma de promover efeitos fisiológicos positivos para que a função materna fosse garantida. Aos médicos e aos profissionais de Educação Física, eram requisitados a supervisão e o controle da prática esportiva feminina com o objetivo principal de desenvolver esse corpo em benefício da reprodução e da manutenção dos ideais da família burguesa. A intenção, portanto, era anular ou deixar em segundo plano as próprias conquistas das mulheres no campo esportivo argentino.

Temática semelhante foi abordada por Maria Silva Di Liscia e Stella Maris Cornelis ao tratarem da prática majoritariamente feminina do basquete na Argentina dos anos 1930, em especial no interior do Instituto Nacional de Educación Física. Nascido como um esporte voltado para adolescentes de ambos os sexos, o basquete passaria nesses anos a ser recomendado e praticado especialmente pelas mulheres. A partir do referencial teórico conferido pela história do corpo, as autoras elaboram uma primorosa revisão bibliográfica sobre o tema, de modo a estabelecerem a importância da produção acadêmica de Michel Foucault para as pesquisas que indagam o papel da ciência na constituição de saberes sobre o corpo. Apoiadas nesse referencial, problematizaram as representações construídas por setores da sociedade argentina para que a prática do basquete se definisse nesse período como eminentemente feminina, calcada em valores como docilidade e leveza, apesar de suas praticantes, frequentemente, se identificarem como atletas, e não unicamente como representantes do "sexo frágil". 
No capítulo escrito por Ricardo Martinéz Mazzola, encontramos uma delimitação temática bastante precisa acerca dos olhares que os socialistas argentinos estabeleceram sobre a cultura física nas primeiras décadas do século XX. A saúde parece ser o seu pano de fundo, sobretudo ao se eleger a reivindicação dos socialistas argentinos de democratização de práticas corporais consideradas saudáveis. Inicialmente, esses grupos se voltaram à condenação dos jogos de azar, incluindo-se as corridas de cavalo e as suas apostas, os jogos de carta e o boxe. Para esses grupos, essas atividades poderiam destruir as energias dos trabalhadores e desviar suas atenções de causas políticas. Por outro lado, enalteciam e reivindicavam a democratização da ginástica e das práticas corporais ao ar livre, semelhantes àquelas realizadas no aristocrático balneário de Mar del Plata, como uma forma de aproveitar o tempo livre e melhorar a saúde, atividades que à época eram reservadas exclusivamente às classes mais ricas. No que tange especialmente ao esporte, se este fora inicialmente tratado com desinteresse pelos socialistas argentinos, e mesmo com desconfiança - como o caso do turfe, do boxe e da esgrima -, com o futebol, o cenário começaria a se alterar no início do século XX. Isso porque consideravam este esporte como significativa estratégia de inserção em espaços de sociabilidade cada vez mais importantes para as classes populares, tendo organizado seu próprio campeonato futebolístico, denunciado as condutas dos dirigentes de clubes e ligas e lamentado que a prática se tornava cada vez menos cavalheiresca e mais violenta.

A quase totalidade das pesquisas apresentadas na obra abarca o período compreendido entre as duas últimas décadas do século XIX e primeira metade do século XX, com exceção da investigação realizada por Carolina Ferrante, que se dedicou à fase de institucionalização do esporte adaptado na cidade de Buenos Aires, entre os anos de 1961-1976. Tomando o corpo do deficiente físico como tema e problema de pesquisa, a autora analisa a sua inserção no processo de criação de um órgão administrativo especialmente dedicado à promoção do esporte adaptado na Argentina. A prática do esporte pelo deficiente físico estava pautada pela lógica da superação individual, com a clara intenção de torná-lo um membro útil à sociedade. Desse modo, a exigência da eficiência máxima, associada à ideia de um ser produtivo, atendia às expectativas exigidas por extratos específicos da sociedade. Entre embates discursivos e os papéis exercidos por diferentes agentes sociais, tanto por médicos quanto pelos praticantes, a autora observa que predominava no esporte adaptado argentino uma meritocracia individual tributária de valores associados à moral burguesa. 
Apesar de o título Miradas médicas sobre la cultura física en Argentina sugerir que as investigações apresentadas no livro se concentram exclusivamente no âmbito do discurso médico, duas pesquisas o extrapolam, centralizando suas análises no discurso militar. É assim que Laura Marcela Méndez analisa a grande promoção das associações de tiro e de grupos escoteiros no sul argentino durante as primeiras décadas do século XX como reflexo da instauração de um sentimento de medo de perda da Patagônia para o Chile, ou seja, de ameaça à soberania territorial. A autora demonstra que ambas as entidades incorporavam o ideal de salvaguarda da pátria, de seu território e de sua moral contra inimigos externos, embasando um sentimento coletivo de unidade nacional e de pertencimento a uma mesma identidade cultural. Essas associações instituíam rituais nacionalistas, ideais de conquista, de virilidade e tiveram entre seus membros personalidades ligadas diretamente ao exército e à corporação policial; desse modo, para seus associados, a participação era fator de prestígio social, de visibilidade na esfera pública, além de promoverem espaços de sociabilidade para a construção de um ideal argentino. A partir de uma associação entre a nação e sua natureza, o escotismo procurou ensinar a geografia e a história nacional como elementos de amor à pátria, enquanto as associações de tiro buscaram impulsionar o aprendizado do manejo de armas de fogo para a defesa nacional.

Nesta mesma linha temática encontra-se o capítulo desenvolvido por Ariel Fresia e Maria Andrea Nicoletti, cujo tema é também o discurso militar-patriótico, mas em sua relação com a moral religiosa propagada na Argentina pelas escolas particulares da congregação salesiana. As principais ferramentas pedagógicas dessa congregação eram a recreação, o jogo, o teatro, os passeios, as excursões e os exercícios corporais. Entre práticas recreativas e reformas dos métodos de ensino por ela pregadas, observava-se na Argentina uma associação aos ideais militares-patrióticos para fazer frente a um processo de laicização da escola pública posto em prática no país durante as primeiras décadas do século XX. Desse modo, a prática cotidiana do fazer educativo dessa congregação acabava por pender muito mais para a primazia do espírito da obediência do que para um pensamento pedagógico necessariamente aberto e moderno.

A obra que ora se apresenta ao público leitor traça um sofisticado panorama da história de uma cultura física que se desenhou na Argentina no período e que se expressou de modo bastante claro no que se denominou de Educação Física e esportes, não apenas no que diz respeito ao universo escolar, mas também no que concerne aos espaços consolidados para a prática de exercícios físicos, jogos e esportes, principalmente na cidade de Buenos Aires. 


\section{NOTAS}

${ }^{1}$ O Instituto Nacional de Educación Física foi a primeira instituição de formação superior em Educação Física na Argentina.

Recebido: 25/11/2014

Aprovado: 15/04/2014

Contato:

Universidade Estadual de Campinas Faculdade de Educação Física.

R. Érico Veríssimo, 701 Barão Geraldo Caixa-postal: 6134 Campinas |SP|Brasil CEP 13.083-851 
